\title{
Dino no Vale dos Dinossauros: um Recurso Educacional Digital para Auxiliar Conceitos Básicos de Contagem
}

\author{
Erasmo Dantas da Silva Fernandes ${ }^{1}$, Márcio Matoso de Pontes ${ }^{3}$, Arianny de Sousa \\ Lira $^{2}$, Darlene Alves Leitão ${ }^{2}$, Marlon Procópio Martins', Thais Kelly da Silva \\ Moreira $^{1}$, Juscileide Braga de Castro ${ }^{12}$.
}

${ }^{1}$ Faculdade de Educação (FACED) - Universidade Federal do Ceará (UFC) - Fortaleza, CE - Brasil.

${ }^{2}$ Grupo de Pesquisa e Produção de Ambientes Interativos e Objetos de Aprendizagem PROATIVA. Instituto UFC Virtual

3Pós-Graduação em Ensino de Ciências e Matemática (PGECM) - Instituto Federal de Educação Tecnológica do Ceará (IFCE) - Fortaleza, CE - Brasil

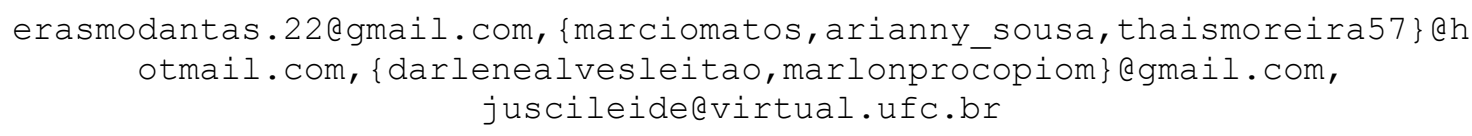

\begin{abstract}
This article aims to present and analyze the prototype digital educational resource (DER) named, Dino in the Valley of the Dinosaurs, developed to meet the counting skills planned by the National Curricular Common Base (NCCB) for 4th year classes of Elementary School. It was created from the use of Scratch software, a programming language used to create animated stories, games and other interactive programs. Among the results, we verified that the DER enabled learning of mathematical concepts, as well as reflections and methodological analyzes, assisting in the process of the use and production of digital information and communication technologies (DICT).
\end{abstract}

Resumo. Este artigo tem como objetivo apresentar e analisar o protótipo de um recurso educacional digital (RED) denominado, Dino no Vale dos Dinossauros, desenvolvido para atender às habilidades de contagem previstas pela Base Nacional Comum Curricular (BNCC) para turmas do $4^{o}$ ano do Ensino Fundamental. Foi criado a partir da utilização do software Scratch, uma linguagem de programação utilizada para criar histórias animadas, jogos e outros programas interativos. Dentre os resultados, verificamos que o RED viabilizou aprendizagens de conceitos matemáticos, como também, reflexões e análises metodológicas, auxiliando no processo do uso e de produção de tecnologias digitais de informação e comunicação (TDIC).

\section{Introdução}

É comum se constatar, em diferentes escolas brasileiras, as dificuldades que estudantes possuem em relação à Matemática. Avaliações de larga escala, como o Sistema de Avaliação da Educação Básica (SAEB), verificaram que cerca de 83,30\% dos estudantes brasileiros, cursando o $5^{\circ}$ ano do Ensino Fundamental, não estão no nível considerado 
adequado em Matemática, ou seja, acima de 7, em uma escala que vai de 0 a 10 [Brasil 2017a].

Pesquisas [Maia 2012; Nacarato, Passos e Mengali 2009] também apontam que algumas destas dificuldades enfrentadas por estudantes dos anos iniciais também podem ser verificadas em professores da Educação Básica, como os que atuam na Educação Infantil e nos anos inicias do Ensino Fundamental.

Neste contexto, entende-se a importância de promover, desde a formação inicial, ações que contribuam na compreensão de conceitos matemáticos, teorias e metodologias que possam auxiliar estes docentes a possibilitarem a compreensão da Matemática por seus estudantes.

Estudos feitos por Prado (2000) sobre formas de apoio ao ensino da Matemática nos justificam a importância da utilização de alguns recursos que auxiliem o professor para contextualizar os conteúdos abordados. Como exemplo, a criação e/ ou aprimoramento de jogos matemáticos. Para desenvolver esta proposta é preciso tempo para o planejamento e desenvolvimento de projetos que envolvam problemas do cotidiano escolar, e por meio desses problemas, objetiva-se a possibilidade de serem agregados cálculos, para que os alunos possam ter maior aproximação com o conhecimento matemático [Prado 2000].

Embora seja possível se utilizar diferentes abordagens metodológicas e recursos didáticos, optou-se por explorar uma das competências apontada pela Base Nacional Comum Curricular (BNCC), em que prevê a cultura digital nas escolas, seja para compreender, utilizar e/ou criar tecnologias digitais, como possibilidade de produzir informação e conhecimento [Brasil 2017b].

Além das competências, explorou-se ainda na BNCC, as habilidades matemáticas previstas para serem trabalhadas em cada ano escolar, buscando a integração entre habilidades da Matemática com as de outras áreas de conhecimento, como a Geografia e a História.

Assim, este artigo tem como objetivo apresentar e analisar o protótipo de um recurso educacional digital (RED) Dino no Vale dos Dinossauros, desenvolvido no âmbito da formação inicial, como forma de refletir conceitos matemáticos e abordagens metodológicas estudadas ao longo de uma disciplina do curso de Pedagogia.

Essa abordagem de pesquisa, assemelha-se com o trabalho desenvolvido por Castro et al (2017), em que os estudantes de Pedagogia utilizaram e apresentaram o Design Thinking como um processo de produção de RED para o Ensino de Matemática sobre conteúdos como: álgebra, padrões, medidas antropométricas, gráficos e situação de multiplicação. A pesquisa apresenta evidências de que esta abordagem construcionista contribuiu para "a compreensão conceitual, teórica e metodológica dos conteúdos trabalhados" [Castro et al 2017, p. 485].

Diante das questões citadas, este artigo organiza-se da seguinte forma: a introdução, já descrita, o contexto e desenvolvimento, a apresentação do recurso educacional digital (RED), Dino do Vale dos Dinossauros, e por fim, as considerações finais.

\section{Contexto e Desenvolvimento}

Dino no Vale dos Dinossauros é um RED que foi elaborado na disciplina de Ensino de Matemática do Curso de Pedagogia da Faculdade de Educação (FACED) da Universidade Federal do Ceará (UFC), durante o semestre 2018.2. 
A elaboração considerou a abordagem do Design Thinking, na qual contempla 4 etapas: (1) imersão; (2) análise e síntese; (3) ideação e (4) prototipação e testes; sendo estas etapas não lineares, já que, durante a produção, pode-se verificar a necessidade de voltar às etapas iniciais [Castro et al 2017].

No decorrer do processo, definiu-se como público alvo os estudantes do $4^{\circ}$ ano do Ensino Fundamental devido a este nível de ensino ser área de atuação de um dos proponentes do grupo, contudo, reforçamos que a aplicação do jogo pode adequar-se a outros níveis escolares, por meio do acompanhamento do professor como mediador no processo de ensino e de aprendizagem.

Para a produção do RED utilizou-se o Scratchı, ferramenta que pode ser utilizada por professores que desejam construir simulações e jogos autorais de maneira simples. Não é necessário um entendimento vasto e complexo de programação, pois o Scratch é intuitivo. A sequência de comandos é realizada a partir de uma linguagem de programação, na qual o computador compreende e executa as ações programadas, além de permitir o reuso de jogos disponíveis na plataforma, no qual o usuário pode utilizá-los como base de programação no desenvolvimento de um novo jogo.

A seguir será apresentado o RED, Dino no Vale dos Dinossauros2, a narrativa interdisciplinar, e os desafios apresentados em cada fase, além de reforçar o papel do professor como mediador no processo de ensino e de aprendizado, bem como pesquisas relacionadas ao uso das tecnologias digitais de informação e comunicação (TDIC).

\section{Apresentação do protótipo produzido: Dino no Vale dos Dinossauros}

O RED apresenta uma proposta de ensino interdisciplinar, apresentando como objeto de conhecimento matemático os problemas de contagem presentes na unidade temática números, da BNCC. Relaciona-se também conhecimentos de História ao explorar como era a representação de desenhos e símbolos pelos nossos antepassados, e de Geografia, ao apontar o Piauí como localização do maior sítio arqueológico do Nordeste.

Em relação aos conhecimentos matemáticos, visa-se desenvolver no aluno a habilidade de resolver problemas simples de contagem, com suporte de imagens, para determinar o número de elementos possíveis ao se combinar cada elemento de uma coleção com todos os elementos de outra, por meio de estratégias e registros pessoais (EF04MA08) [Brasil, 2017b].

Sabe-se que os alunos do $4^{\circ}$ ano, de acordo com o que é proposto pela BNCC, devem desenvolver a habilidade (EF04MA08), e nessa perspectiva surgiu a proposta de elaboração de um recurso que deu origem ao protótipo Dino no Vale dos Dinossauros.

O recurso foi produzido utilizando a linguagem de programação Scratch, escolhido por ser uma ferramenta de fácil manuseio e acesso livre. Resnick (2012), foi o idealizador do Scratch juntamente com o grupo Media Lab. do MIT, no qual apresenta como seu objetivo tornar a codificação acessível e atraente para todos, por meio da linguagem de programação. O Scratch pode ser utilizado online por meio de um cadastro de acesso ou após download e instalação.

Dessa forma o protótipo traz em seu contexto um passeio pelo vale dos dinossauros, em que os alunos irão desbravar situações de contagem, com uma narrativa que retrata a história do nosso Nordeste. O Dino, personagem do recurso, é um dinossauro

1 Disponível através do endereço eletrônico: https://scratch.mit.edu/

2 Disponível em: https://scratch.mit.edu/projects/324089549/fullscreen/ 
que mora no maior sítio arqueológico de fósseis do país, Parque Nacional da Serra da Capivara localizado no estado do Piauí, região noroeste do Nordeste.

O material desenvolvido é construído por níveis de dificuldades, e as fases foram desenvolvidas em formas de perguntas, na qual foram escolhidos em pesquisa a partir de livros didáticos do $4^{\circ}$ ano. Cada pergunta respondida certa é mais um passo para o jogador vencer o jogo.

Enquanto protótipo, o recurso ainda não possui em sua programação situações de resposta a falhas cometidos pelo jogador, apesar de não possuir ainda uma configuração concluída sabe-se da importância de uma ampliação no recurso de situações que permita ao usuário uma reflexão diante de um possível erro.

Para a criação do jogo foi utilizado o processo de programação, que tem início quando o sujeito decide externalizar uma ideia para o computador, e após a informação ter sido descrita, o computador realiza e executa as sequências de comando, apresentando ao sujeito um resultado (Figura 1).

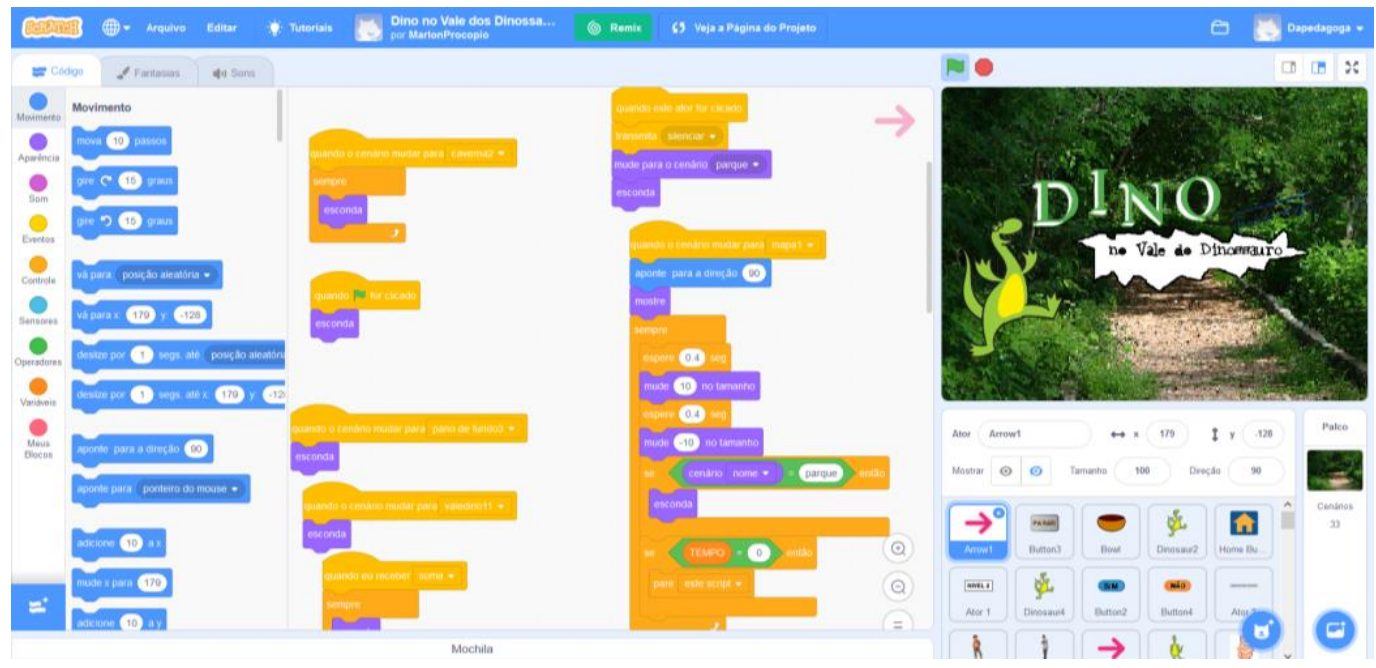

Figura 1. Interface de usuário: programação do jogo no Scratch

As sequências de atividades no jogo foram pensadas levando em consideração atividades do dia a dia do Dino, durante a hora de comer e em suas brincadeiras com os amigos no Vale.

A abertura do jogo se dá com a escolha do jogador, existem dois personagens, uma menina e um menino, o jogador escolhe seu avatar e está pronto para cumprir os desafios. Logo após o narrador, Dino, irá se apresentar falando um pouco sobre o local onde vive, assim ocorrendo uma interdisciplinaridade e integração dos conteúdos de Matemática, História e Geografia.

No primeiro desafio, representado na Figura 2, Dino irá em busca de alimento no Vale, o jogador irá escolher a fruta de sua preferência, podendo ser caju, buriti ou bacuri, por serem frutas tropicais típicas do Piauí. Ao fazer sua escolha, será cronometrado um tempo de 30 segundos para que se possa recolher a maior quantidade possível da fruta selecionada. Ao finalizar o tempo, teremos o momento em que a capivara informa ao jogador quantas frutas foram recolhidas no desafio, representando a habilidade EF04MA08, assim como o questiona com algumas perguntas envolvendo as operações de soma e subtração, de forma a abordar no jogo situações para auxiliar o aluno a desenvolver habilidades presentes na BNCC. 
Visa-se assim, no decorrer do primeiro desafio, que o aluno possa resolver e elaborar problemas com números naturais envolvendo adição e subtração, utilizando estratégias diversas, como cálculo, cálculo mental e algoritmos, além de fazer estimativas do resultado (EF04MA03) e utilizar as relações entre adição e subtração, bem como entre multiplicação e divisão, para ampliar as estratégias de cálculo (EF04MA04) [Brasil, 2017b].
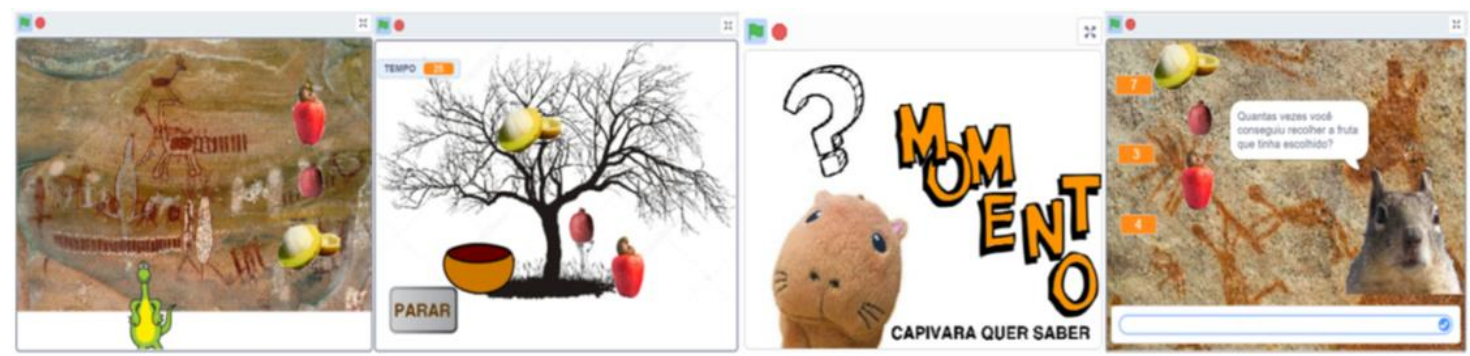

Figura 2. Sequência da fase inicial do jogo

Tendo êxito segue a narrativa sobre seu dia a dia, o segundo desafio é na casa do Dino, que encontra-se situada em uma caverna, nessa fase a pergunta direciona-se para a escolha de diferentes possibilidades de combinar a cor de roupa que ele terá, diante das peças disponíveis em seu guarda roupa, habilidade EF04MA08 e reconhecer as frações unitárias mais usuais $\left(\frac{1}{2}, \frac{1}{3}, \frac{1}{4}, \frac{1}{5}, \frac{1}{10}\right.$ e $\left.\frac{1}{100}\right)$, como unidades de medida menores do que uma unidade, utilizando a reta numérica como recurso (EF04MA09) [Brasil, 2017b].

Segue para o terceiro desafio, teremos mais dois personagens inseridos, Hepe e Pop, amigos do Dino que irão ajudá-lo na busca de fósseis no Parque Nacional da Capivara. O desafio será sobre a quantidade de fósseis recolhidos por cada personagens. Ao terminar as buscas o jogador responderá uma sequência de perguntas (Figura 3), permite assim um contato com as habilidades EF04MA03 e EF04MA04.
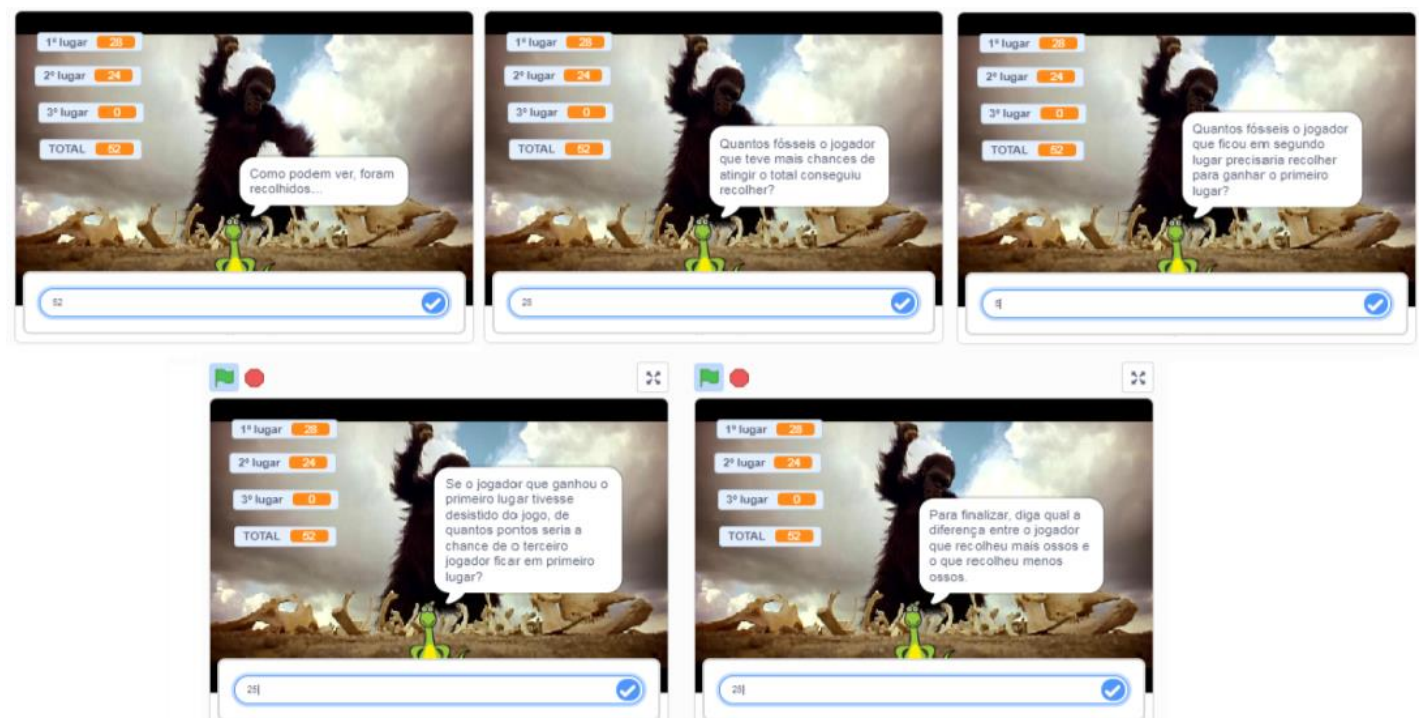

Figura 3. Sequência de perguntas - terceiro desafio do jogo

Ressaltamos a importância dessa incorporação de práticas que permitem que, o professor se torne atuante no processo de aprendizagem. Nessa perspectiva, é importante ressaltar que o aluno como aprendiz em um processo de aprendizagem, quando consegue incorporar os elementos apresentados, a aprendizagem se torna algo simples, e de certa forma proveitoso, caso contrário, o processo se torna extremamente difícil [Papert 1985]. 
Desta forma, reforça-se a importância da inserção de práticas que envolvam o uso das TDIC em formações iniciais e continuadas. Que possibilitem aos docentes, esse contato com práticas que utilizem as TDIC e que permitam trocas de ideias entre demais professores, ou profissionais da área da educação [Leitão 2018].

\section{Considerações Finais}

A escola está inserida em um contexto, no qual as TDIC estão cada mais presentes no campo educacional. É perceptível que essa visibilidade tecnológica, vem modificando as relações na sociedade. E dentro do espaço escolar essa realidade não é diferente. Nessa perspectiva, a produção e uso de recursos tecnológicos, pode vir a colaborar positivamente para o processo de aprendizagem [Leitão 2018].

Desta forma, ressalta-se que diante da proposta de criação com Scratch existe uma percepção, por parte do grupo idealizador, de que, a capacidade de escrever códigos é importante diante da sociedade atual. Resnick (2013) enfatiza que quando se aprende a programar no Scratch, aprendem-se estratégias importantes para resolver problemas, desenvolver projetos e partilhar ideias.

Evidencia-se deste modo, as contribuições que esse processo de construção e reflexão do recurso podem oportunizar aos envolvidos no processo de ensino e que puderam ser vivenciadas pelos participantes, tais como: a apropriação das habilidades que são propostas pela BNCC, a criação de mídias digitais e a reflexão sobre a aprendizagem da programação. Neste sentido, visualizamos o processo de criação como facilitador de reflexões conceituais e metodológicas, auxiliando no processo do uso e de produção das TDIC aliados ao ensino de Matemática.

É importante elencar que o recurso, enquanto protótipo, ainda não foi utilizado em sala de aula, e possui algumas limitações, como fases ainda não concluídas, e implementações no quesito do potencial pedagógico. O recurso precisa ser aperfeiçoado, trazendo mais fases e situações que permitam aprendizagens de conceitos matemáticos, contemplando outras habilidades da BNCC.

Acreditamos que para o professor, a formulação de problemas com a interação dos jogos digitais, é uma estratégia de ensino que fornece subsídio aos alunos em relação aos conceitos matemáticos, além de permitir a produção colaborativa. Esperamos permitir novos olhares e novas perspectivas de práticas pedagógicas, com ênfase na formação do estudante para aprendizagem significativa com o envolvimento de TDIC no âmbito educacional.

Finalizamos esse artigo, cientes da importância de ações que propicie reflexões e discussões acerca do uso de TDIC, com o objetivo de levar para a escola práticas ativas de ensino que permitam que o processo de aprendizagem seja significativo. Apresentamos o jogo, Dino no Vale dos Dinossauros, um protótipo de recurso digital por meio do Scratch, como auxílio no ensino de conceitos básicos de contagem. Contudo esperamos que outras questões possam ser abordadas e discutidas com novos olhares sobre esse tema, trazendo novas contribuições para o processo de ensino e de aprendizado.

\section{Referências}

Brasil. Ministério da Educação. (2017a) “SAEB 2017”. Brasília: INEP.

Brasil, Ministério da Educação. (2017b) "Base Nacional Comum Curricular”. Brasília: MEC/ Secretaria de Educação Fundamental. 
Castro, J. B.; Soares, I. O.; Vianna, E. P. N.; Sousa, J. S. (2017) "Lógica Criativa: a construção de mídias digitais para o ensino de matemática". In: Anais dos Workshops do VI Congresso Brasileiro de Informática na Educação (WCBIE 2017). VI Congresso Brasileiro de Informática na Educação (CBIE 2017), Disponível em: <http://www.brie.org/pub/index.php/wcbie/article/view/7431/5227>. Acesso em: 23 mar. 2019

Leitão, D. A. (2018) "Um olhar pedagógico sobre o processo de construção de recursos digitais de matemática com Scratch”. Fortaleza. 54f. Monografia, Curso de Pedagogia - Universidade Federal do Ceará (UFC).

Maia, D. L. (2012) "Ensinar Matemática com o uso de tecnologias digitais: um estudo a partir da representação social de estudantes de Pedagogia". 2012. 190p. Dissertação (Mestrado Acadêmico em Educação) - Universidade Estadual do Ceará, Fortaleza.

Nacarato, A. M.; Mengali, B. L. da S.; Passos, C. L. B. (2009) "A matemática nos anos iniciais do Ensino Fundamental: tecendo fios do ensinar e do aprender". Belo Horizonte: Autêntica.

Papert, Seymour. (1985) "Logo: Computadores e Educação". $3^{\mathrm{a}}$ ed. São Paulo: Editora brasiliense s.a.

Prado, I. G. (2000) "Ensino de Matemática: O Ponto de Vista de Educadores e de seus Alunos sobre Aspectos da prática pedagógica". Rio Claro. 255f. Tese de Doutorado Educação Matemática, Universidade Estadual Paulista, Instituto de Geociência e Ciências exatas (UNESP).

Resnick, Mitch. (2012) "Let's teach kids to code". TED: Ideas Worth Spreading. Disponível: <https://www.ted.com/talks/mitch_resnick_let_s_teach_kids_to_code>. Acesso em: 11 Dez 2018

Resnick, M. (2013) "Learn to code, code to learn". Technology in School, [Burlingame], May 8. Disponível em: <https://www.edsurge.com/news/2013-05-08-learn-to-codecode-to-learn>. Acesso em: 01 Dez 2018. 